\title{
The Paris Agreement and Net-Zero Emissions: What Role for the Land-Sector?
}

\section{Background}

The Fifth Assessment Report of the Intergovernmental Panel on Climate Change (IPCC), published in 2014, sent a clear message to the world: climate science concluded that the warming of the climate system is unequivocal'. ${ }^{1}$ Further, the IPCC noted that '[h] uman influence on the climate system is clear', driven largely by economic and population growth since the pre-industrial era, leading to unprecedented concentrations of greenhouse gases (GHG) and being extremely likely the dominant cause of the observed warming since the mid-20th century. ${ }^{2}$ The IPCC also warned that mitigation pathways likely to limit global warming to below $2^{\circ} \mathrm{C}$ relative to pre-industrial levels, which is recommended to avoid even more negative effects of climate change, would require substantial emissions reductions over the next decades and 'near-zero' emissions of $\mathrm{CO}_{2}$ and other GHGs by the end of the century. ${ }^{3}$

One year later, the Paris Agreement (PA) was adopted to 'strengthen the global response to the threat of climate change', committing member States to hold the increase in the global average temperature to 'well below $2{ }^{\circ} \mathrm{C}$ above pre-industrial levels and to pursue efforts to limit the temperature increase to $1.5^{\circ} \mathrm{C}$ above pre-industrial levels, recognizing that this would significantly reduce the risks and impacts of climate change' (art. 2, paragraph 1, lit. a). In order to achieve this goal, the PA provides that 'Parties aim to reach global peaking of greenhouse gas emissions as soon as possible (...) and to undertake rapid reductions thereafter in accordance with best available science, so as to achieve a balance between anthropogenic emissions by sources and removals by sinks of greenhouse gases in the second half of this century' (art. 4, paragraph 1). ${ }^{4}$ Following the adoption of the PA, in October 2018 the IPCC released another important report on the treaty's $1.5^{\circ} \mathrm{C}$ goal, warning that human activities are estimated to have already caused a warming of approximately $1.0^{\circ} \mathrm{C}$ to date and that under a business-as-usual scenario, warming would likely to reach $1.5^{\circ} \mathrm{C}$ between 2030 and $2052 .{ }^{5}$ The report highlighted that pathways keeping global warming within the $1.5^{\circ} \mathrm{C}$ goal require a decline of global net anthropogenic $\mathrm{CO}_{2}$ emissions of about 40-60\% from 2010 levels by

DOI: $10.21552 / \mathrm{cclr} / 2021 / 1 / 3$

$1 \quad$ IPCC, 'Climate Change 2014: Synthesis Report. Contribution of Working Groups I, II and III to the Fifth Assessment Report of the Intergovernmental Panel on Climate Change' (2014) 2.

2 ibid 4.

3 ibid 20.

4 It is reported that such complex wording was finally adopted during PA negotiations, as references to "carbon neutrality" or "net zero emissions" were considered too politically controversial, with earlier drafts of the Agreement having included proposals such as reducing emissions by $70-95 \%$ by 2050 compared to 2010 levels, or $60-90 \%$ compared to 1990 levels, to encourage the peaking of emissions in the near future and steep reductions thereafter. Oxford Climate Policy/ECBI, Guide to the Paris Agreement, 2020, page 45.

5 IPCC, 'Global Warming of $1.5^{\circ} \mathrm{C}$ : an IPCC Special Report on the impacts of global warming of $1.5^{\circ} \mathrm{C}$ above pre-industrial levels and related global greenhouse gas emission pathways, in the context of strengthening the global response to the threat of climate change, sustainable development, and efforts to eradicate poverty' (2018) 4. 
2030, reaching net-zero around 2050, ${ }^{6}$ while non- $\mathrm{CO}_{2}$ emissions need to reach net-zero around $2070 .^{7}$ Importantly, global GHG emissions need to stay net-negative thereafter.

Achieving 'net-zero GHG emissions' (or 'climate neutrality') has since become one of the most relevant targets of climate mitigation policies worldwide. Importantly, this goal requires not only rapid and deep GHG emission reductions but simultaneously the protection of GHG sinks and the significant enhancement of GHG removals. In this context, the 'land sector' plays a crucial role. The capacity of terrestrial sinks and reservoirs, such as soils, wetlands, peatlands, mangroves and forests to sequester and store GHGs, as well as the adoption of practices and processes in the use and management of land (e.g. management of practices in agricultural land, avoiding conversion of forest land to other uses) to limit emissions from and enhance removals in this sector, will be key achieving the netzero goal.

Against this background, this Special Issue of CCLR aims to shed light on how legislation in the land sector can contribute to achieving 'net-zero' GHG emissions, providing an analysis of the topics involved and case studies on how countries are legislating on related areas. The Special Issue was prepared through a collaboration of members of the IUCN World Commission on Environmental Law (WCEL)'s Climate Change Specialists Group (CCSG), which is preparing an extended IUCN report on this subject to be published by $2022 .{ }^{8}$

\section{Understanding 'Net-Zero' GHG Emissions}

As countries move forward with the implementation of the PA, including the design and implementation of mitigation targets and measures based on 'net-zero' GHG emissions, important questions arise with regards to defining the key elements in this goal, including 'net-zero emissions', how to set the time frame for reaching this goal, which sectors and GHGs to include, and the role of carbon removal and storage and international transfers in achieving net-zero emissions, among others. ${ }^{9}$

A first important nuance relates to the focus of the net-zero target. Several GHGs play a role in global warming. However, cumulative carbon dioxide $\left(\mathrm{CO}_{2}\right)$ emissions are reported by the IPCC as the primary determinant of temperature change in this century, noting that '[l]imiting global mean temperature increase at any level requires global $\mathrm{CO}_{2}$ emissions to become net zero at some point in the future' ${ }^{10}$ At the same time, other relevant GHGs include methane $\left(\mathrm{CH}_{4}\right)$, nitrous oxide $\left(\mathrm{N}_{2} \mathrm{O}\right)$, hydrofluorocarbons (HFCs), perfluorocarbons (PFCs), sulfur hexafluoride $\left(\mathrm{SF}_{6}\right)$, and nitrogen trifluoride $\left(\mathrm{NF}_{3}\right)$. Although some

\footnotetext{
ibid 10 .

ibid C.1.

The project description can be consulted here: <https://www.iucn.org/commissions/world-commission-environmental-law/our-work/climate -change/getting-zero> accessed 8 May 2021.

9 World Resources Institute (WRI), 'Designing and Communicating Net-Zero Targets' (2020) Working Paper, 3.

10 (n 5) 4
} 
of them are 'shorter-lived' (such as methane and HFCs) and do not accumulate in the atmosphere for a long time, they are still strong drivers of climate change. Nearly all IPCC pathways consistent with the $1.5^{\circ} \mathrm{C}$ goal include net-zero $\mathrm{GHG}$ emissions between 2050 $\left(\mathrm{CO}_{2}\right)$ and $2070\left(\right.$ non- $\left.\mathrm{CO}_{2}\right){ }^{11}$

A second key issue relates to terminology, as a variety of terms has been used by public and private stakeholders to designate such targets, including 'net-zero emissions' and 'zero emission' targets, 'climate neutrality,' 'carbon neutrality,' 'deep decarbonisation', among others. ${ }^{12}$ In addition to understanding this terminology, the scale is also relevant, i.e. whether these terms refer to domestic or international targets. Firstly, it should be noted that while 'carbon neutrality' refers to net-zero emissions of $\mathrm{CO}_{2}$ only, 'climate neutrality' has refers to net-zero emissions of all GHGs $\left(\mathrm{CO}_{2}\right.$ and non- $\left.\mathrm{CO}_{2}\right)$. In general, the following definitions are useful: ${ }^{13}$

- Net-zero emissions:

- at the global level, 'net-zero GHG emissions' refers to a global balance between anthropogenic emissions and removals of GHGs over a given time period (typically a year);

- at the country level, net-zero emissions (excluding international transfers of GHG mitigation outcomes) refers to keeping GHG emissions from sources within the national territory in the target year in balance with GHGs removed from the atmosphere by sinks within the country's territory in the target year. These definitions refer to anthropogenic GHG emissions and removals in units of ' $\mathrm{CO}_{2}$ equivalent'. Countries can further specify the proportion of the target being met through emission reductions versus removals (in either definition) or the proportion of domestic GHG mitigation versus international transfers of GHG mitigation outcomes (in the second definition).

- Based on these definitions, countries might have, within a given time period, net-zero emissions, net-positive emissions (i.e. annual GHG emissions are higher than annual GHG removals within the territory), or net-negative emissions (i.e. annual GHG emissions are lower than annual GHG removals within the territory).

- Other important elements include the target time frame (i.e. range of years), boundary (i.e. comprehensive or partial coverage of GHGs) and the use or exclusion of international transfers of GHG mitigation outcomes (e.g. to include or not transfer of carbon credits).

- Source: A physical unit or process that releases a GHG into the atmosphere (such as fuel combustion, cement production, livestock management, and waste disposal).

- Sinks: A physical unit or process that removes and stores a GHG from the atmosphere (such as photosynthesis and other biological sinks, geochemical sinks and direct air capture and storage).

- Removals: transfer of a GHG (primarily $\mathrm{CO}_{2}$; and therefore also often referred to as 'Carbon Dioxide Removal' $-\mathrm{CDR})^{14}$ from the atmosphere by a sink to long-term storage

12 NewClimate Institute and DataDriven EnviroLab, 'Navigating the Nuances of Net-Zero Targets' (2020) 8.

13 (n 9) 6 - 7.

14 IPCC definition of CDR: 'Anthropogenic activities removing CO2 from the atmosphere and durably storing it in geological, terrestrial, or ocean reservoirs, or in products. It includes existing and potential anthropogenic enhancement of biological or geochemical sinks and direct air capture and storage, but excludes natural $\mathrm{CO} 2$ uptake not directly caused by human activities'. 
within a pool, such as trees, soil, or geologic, terrestrial, oceanic reservoirs, and in products.

Another important point relates to the use or exclusion of offsets towards 'net-zero'. This is a controversial topic and poses some limitations and risks under the PA's global governance framework, including the fact that the treaty envisions a goal of global net-zero GHG emissions ('balance of anthropogenic emissions and removals') in art. 4, paragraph 1. The widespread resort to offsets might help to balance emissions in some countries but might also hamper efforts to increase ambition towards net-negative emissions at large. Moreover, the use of offsets might undermine the efforts of some countries to promote real emission reductions in their territories. Further, if not balanced with appropriate safeguards, offsetting approaches can create conflicts and challenges for host countries in their efforts to enhance domestic ambition. ${ }^{15}$

A further aspect is equity in reaching global net-zero emissions around 2050. While it is understood that this is a global goal, some countries might need longer to reach it (see art. 4.1 PA). This, in turn, means, that if the timeline of reaching net-zero emissions is not to be overshot, those countries with the greater capacity and responsibility need to take deeper cuts and to reach territorial net-zero or net-negative emission far ahead of 2050, in order to allow countries which need longer to also get there by 2050 . They might also be required not to contribute to increasing emissions elsewhere through the 'export' of emissions in whatever way and manner; making it more difficult to reach a global balance. This is in line with the principle of common but differentiated responsibilities and respective capabilities, in light of different national circumstances, as included in art. 2.2 of the PA. ${ }^{16}$ A positive example in this regard is New Zealand's recent announcement of a carbon-neutrality target already for $2025 .{ }^{17}$

Another important aspect concerns CDR measures and technologies. While the exploration, development and deployment of CDR are considered key for the achievement of the PA, such technologies and practices are in their early stages, and uncertainties related to methodologies for calculating the impact of those measures, as well as questions about the permanence of carbon storage, mean that they still need time for further development. ${ }^{18}$ In this regard, support for 'nature-based solutions' should be considered especially attractive, in addition to the multitude of environmental and social co-benefits that they entail if correctly and carefully safeguarded. ${ }^{19}$

The 'net-zero' goal is also related to the 'mid-century long-term low greenhouse gas emissions development strategies' (long-term strategies, or LTS) envisioned in the PA (art. 4, paragraph 19), which were expected to be communicated by PA member parties in

15 (n 8) 27.

16 Christina Voigt and Felipe Ferreira, 'Dynamic Differentiation: The Principles of CBDR-RC, Progression and Highest Possible Ambition in the Paris Agreement' (2016) 5 Transnational Environmental Law 2, 285-303.

17 Climate Emergency Declaration, 'New Zealand Declares a Climate Emergency' <https://climateemergencydeclaration.org/new-zealand -declares-a-climate-emergency/> accessed 8 May 2021.

18 (n 8) 28.

19 IPBES, 'Summary for Policymakers of the Global Assessment Report on Biodiversity and Ecosystem Services of the Intergovernmental SciencePolicy Platform on Biodiversity and Ecosystem Services' (2019) 18 - 'Nature-based solutions with safeguards are estimated to provide 37 per cent of climate change mitigation until 2030 needed to meet the goal of keeping climate warming below $2^{\circ} \mathrm{C}$, with likely cobenefits for biodiversity'. 
2020. These strategies represent an important tool for countries to lay out their vision for achieving a low-carbon economy by 2050 while also pursuing sustainable development. It is also considered advantageous for countries to align their NDCs and LTS for consistency and to avoid the lock-in of carbon-intensive behaviour, technologies and policies. ${ }^{20}$

Achieving global net-zero emissions is not only relevant for achieving the PA's temperature goals, but also increasingly urgent as time is moving fast and we are coming close to the limit of a point of no return. The 20202 UNEP Emissions Gap Report (EGR) showed that not only current NDC commitments are insufficient to reach the PA goals, but also that global GHG emissions show no signs of peaking. Although 2020 emissions had brief reductions due to the COVID-19 crisis and associated responses, GHG concentrations in the atmosphere continued to rise and global GHG emissions continued to grow for the third consecutive year in 2019, reaching a record high of $59.1 \mathrm{GtCO} 2 \mathrm{e}$ (including land use change). The report shows that global GHG emissions have grown 1.4 per cent per year since 2010 on average, with a more rapid increase of 2.6 per cent in 2019 due to a large increase in vegetation forest fires. Further, the new or updated NDCs submitted in 2020 are expected to reduce total emissions by less than 1 per cent by 2030, and collectively, fall short of what they promise: full implementation of unconditional NDCs is estimated to still result in a gap of $15 \mathrm{GtCO} 2 \mathrm{e}$ (range: 12-19 GtCO2e) by $2030 \mathrm{com}$ pared with the below $2^{\circ} \mathrm{C}$ scenario; and the emissions gap between implementing unconditional NDCs and the below $1.5^{\circ} \mathrm{C}$ pathway is about $32 \mathrm{GtCO} 2 \mathrm{e}$ (range: 29-36 GtCO2e). Significantly, current NDCs remain seriously inadequate to achieve the PA goals and would lead to a temperature increase of at least $30 \mathrm{C}$ by the end of the century. $^{21}$

There is, however, momentum to reverse these trends. Firstly, there has been a significant wave of announcements of new ambitious emission reduction pledges by several countries, following the 2021 Leader's Summit on Climate. ${ }^{22}$ In addition, global GHG emissions reductions related to COVID19 provide an opportunity for continued ambition, if economic recovery is leveraged to pursue strong decarbonization such as through integration of low-carbon development in COVID-19 rescue and recovery measures, and into new or updated NDCs and long-term mitigation strategies expected to be submitted towards the UNFCCC COP 26 later in $2021 .^{23}$

\section{Why is the Land Sector an Important Piece in this Puzzle?}

The land sector is key for achieving 'net-zero' GHG emissions for several reasons. As noted by the IPCC, land provides the basis for human livelihoods and well-being including food supply, freshwater and multiple other ecosystem services, as well as biodiversity. At

\footnotetext{
20 Climate Watch, 'Explore Long-Term Strategies (LTS)' <https://www.climatewatchdata.org/lts-explore> accessed 8 May 2021.

21 United Nations Environment Programme, 'Emissions Gap Report 2020: Executive Summary' (2020) 4-6.

22 Earth.org, 'The Leader's Summit on Climate 2021: A Summary' <https://earth.org/leaders-summit-on-climate-2021-a-summary/> accessed 8 May 2021.

23 (n 21).
} 
the same time, human activity has already directly affected more than $70 \%$ of the global ice-free land surface. Land can be simultaneously a source and a sink of $\mathrm{CO}_{2}$ due to both anthropogenic and natural drivers, making it difficult to separate anthropogenic from natural fluxes. The IPCC reports that activities related to 'Agriculture, Forestry and Other Land Use (AFOLU)' accounted for around $13 \%$ of $\mathrm{CO}_{2}, 44 \%$ of methane $(\mathrm{CH} 4)$, and $81 \%$ of nitrous oxide (N2O) emissions from human activities globally during 2007-2016, representing $23 \%$ of total net anthropogenic GHG emissions. ${ }^{24}$ This is a significant share, and is, in fact, superior to total emissions from other key sectors such as transportation. Further, agricultural emissions have increased since the turn of the century and, under a business-asusual scenario, and in the face of an expected increase in demand for agricultural products, are expected to rise sharply over the coming years and decades, largely due to the projected increase in the world population (from seven billion today to almost 10 billion in 2050), and changes in diets due to a wealthier middle class particularly in emerging economies. $^{25}$

Agriculture is amongst the sectors already suffering from the heaviest negative impacts of climate change. Extreme weather events are having a profound effect on agricultural performance worldwide and will likely be both more frequent and more intense in the future. Not only does this influence levels of agricultural production, but it is also expected to alter the present conditions of agriculture in almost all countries worldwide, including risks for other important goals like food security. ${ }^{26}$

At the same time, it is pointed out that the mitigation potential of agriculture is large, equivalent to around 6 billion tons of carbon dioxide per year. Around $90 \%$ of this potential lies in increasing carbon sinks, primarily through sequestering carbon in the soil, reducing emissions from inputs (e.g. fertilizers) and livestock management (e.g. manure management), etc. This can be promoted, among other means, through the implementation of practices such as agroforestry, improved grazing land management, crop rotations and fallows, residue management, reduced tillage and the restoration of degraded lands. ${ }^{27}$ In addition, considering that CDR technologies are still in their infancy, as mentioned above, so-called 'nature-based solutions' are gaining increasing recognition due to their huge potential and easier implementation.

Forests also play a crucial role in achieving net-zero emissions. Forests are currently the only proven, large-scale way to take $\mathrm{CO}_{2}$ out of the air. Within the forest sector, avoiding deforestation is the biggest single opportunity, about two thirds of the total potential. Other actions include growing new forests, restoring old forests and better forest management. The IPCC projects that model pathways that limit global warming to $1.5^{\circ}$ require up to 9.5 million $\mathrm{km}^{2}$ increase in forests by 2050 relative to 2010 . Forest management comes, however, with its own set of benefits and challenges as the experiences with REDD+ over the last decade have shown. Including forests management in any net-zero strategy will require careful land planning, safeguards for biodiversity and

24 IPCC, 'Climate Change and Land, an IPCC Special Report on Climate Change, Desertification, Land Degradation, Sustainable Land Management, Food Security, and Greenhouse Gas Fluxes in Terrestrial Ecosystems: Summary for Policy Makers' (2019) 7 - 10.

25 FAO, 'SOFA 2016: Climate Change and Agriculture' (2016) <http://www.fao.org/publications/sofa/2016/en/> accessed 8 May 2021.

26 ibid 6-7.

27 FAO, 'Land Tenure, Climate Change Mitigation and Agriculture' (2011) <http://www.fao.org/climatechange/30353 -0c11859e8b0cac7aabe39520498b2df22.pdf> accessed 8 May 2021. 
indigenous people and local communities, comprehensive and integrated policies for agriculture and forests, as well as addressing deforestation along the supply-chain of products.

With respect to the role of the land sector in reaching global net-zero $\mathrm{CO} 2$ emissions, the IPCC notes that all modelled pathways that limit global warming to $1.5^{\circ} \mathrm{C}$ or below $2^{\circ} \mathrm{C}$ require land-based mitigation and land-use change, with most including different combinations of reforestation, afforestation, reduced deforestation, and bioenergy, but their scale depends on the pursued mitigation portfolio. ${ }^{28}$ Pathways that limit global warming to $1.5^{\circ} \mathrm{C}$ with project up to a 2.5 million $\mathrm{km}^{2}$ increase of non-pasture agricultural land for food and feed crops. ${ }^{29}$ However, due to the multiple objectives which the land sector serves, difficult choices will have to be made. The IPCC notes: 'Such large transitions pose profound challenges for sustainable management of the various demands on land for human settlements, food, livestock feed, fibre, bioenergy, carbon storage, biodiversity and other ecosystem services. Mitigation options limiting the demand for land include sustainable intensification of land-use practices, ecosystem restoration and changes towards less resource-intensive diets. The implementation of land-based mitigation options would require overcoming socio-economic, institutional, technological, financing and environmental barriers that differ across regions. ${ }^{\prime 30}$

For example, land-based climate change mitigation activities can be effective and support biodiversity conservation goals, but it can also negatively impact conservation goals. The 2019 global Global Assessment Report on Biodiversity and Ecosystem Services by the Inter Intergovernmental Science-Policy Platform on Biodiversity and Ecosystem Services (IPBES) warns that «the large-scale deployment of bioenergy plantations and afforestation of non-forest ecosystems can come with negative side effects for biodiversity and ecosystem functions. Nature-based solutions with safeguards are estimated to provide 37 per cent of climate change mitigation until 2030 needed to meet the goal of keeping climate warming below $2{ }^{\circ} \mathrm{C}$, with likely co-benefits for biodiversity. Therefore, land-use actions are indispensable, in addition to strong actions to reduce greenhouse gas emissions from fossil fuel use and other industrial and agricultural activities. However, the large-scale deployment of intensive bioenergy plantations, including monocultures, replacing natural forests and subsistence farmlands, will likely have negative impacts on biodiversity and can threaten food and water security as well as local livelihoods, including by intensifying social conflict.' ${ }^{31}$

\section{The Role of Legislation}

Achieving the global goal of net-zero emissions requires a broad range of policies and measures, including net-zero targets expressed in instruments such as framework legisla-

28 (n 5) 24

29 (n 5) 5, C.2.5.

30 ibid.

31 IPBES, 'Summary for Policymakers of the Global Assessment Report on Biodiversity and Ecosystem Services of the Intergovernmental SciencePolicy Platform on Biodiversity and Ecosystem Services' (2019) <https://ipbes.net/global-assessment> accessed 8 May 2021. 
tion and strategies (e.g., climate laws and long-term strategies); economic instruments (e.g., carbon taxes, subsidy reform, trade and investment policy, and tax incentives); regulatory instruments (e.g., standards for emissions, technology, and product and productions processes); and other approaches, such as information policies, procurement policies, voluntary agreements, and consumer protection standards etc.

While policy goals are obviously important in setting the agenda, legal frameworks have a key role to play, as they not only create binding rules and accountability mechanisms for enforcement, but also the institutions that will implement such targets, as well as empower people to seek justice when these are not upheld. Framework climate change legislation is defined as a 'law or regulation with equivalent status, which serves as a comprehensive and/or unifying basis for climate change policy, addressing multiple aspects or areas of climate change mitigation or adaptation (or both) in a holistic, overarching manner' ${ }^{32}$ Research has shown that overarching framework climate laws and policies are of particular importance in driving climate policy. ${ }^{33}$ These framework climate laws are a trend nowadays, with many countries around the world having passed such types of legislation. ${ }^{34}$ These laws share a number of features, including, for example, legally binding GHG emission reduction targets, GHG emission budgets, review systems and independent institutions to support decision making. Notably, it is reported that, to date, twenty countries and regions adopted net-zero targets in a law or another policy document. ${ }^{35}$

In addition to climate legislation and net-zero targets envisioned in laws and policies, the role of institutions is also key in providing the coordination and leadership to both establish and enforce net-zero targets. In particular, independent climate advisory bodies are noted as important in helping to de-politicise climate policy whilst also scrutinising the government. The UK's Climate Change Committee (CCC), the longest-standing of such bodies (established by the UK Climate Change Act in 2008), has a mandate to advise the UK Government on climate change whilst holding it accountable. Similarly, the French High Council on Climate (HCC) is a body comprised of independent experts established by law with a task to monitor progress in France's climate response and to advise the Government on policy choices and measures, having helped to engage different sectors in the transition towards a net-zero economy. ${ }^{36}$

In addition to framework laws and institutions, legislation in relevant sectors will also play a key role in advancing climate action and enabling the achievement of the net-zero

32 Globe, 'The 2015 Global Climate Legislation Study: A Review of Climate Change Legislation in 99 Countries Summary for PolicyMakers', 12.

33 ibid 17; See also S.M.S.U Eskander and Sam Fankhauser, 'Reduction in Greenhouse Gas Emissions from National Climate Legislation' (2020) Nature Climate Change 10, 750-756.

34 See, for an accurate mapping, the latest edition of the Globe Climate Legislation Study of the LSE Grantham Research Institute on Climate Change and the Environment <http://www.Ise.ac.uk/GranthamInstitute/research/survey-of-climate-legislation-globe/> accessed 8 May 2021.

35 World Resources Institute, 'What does “Net-Zero Emissions" Mean?' <https://www.wri.org/blog/2019/09/what-does-net-zero-emissions-mean-6 -common-questions-answered--gt-- accessed 8 May 2020. The countries mentioned are: Austria, Bhutan, Costa Rica, Denmark, the European Union, Fiji, Finland, France, Hungary, Iceland, Japan, the Marshall Islands, New Zealand, Norway, Portugal, Singapore, Slovenia, Sweden, Switzerland and the United Kingdom. This list only includes countries that adopted a net-zero target. This does not include targets in political speeches, such as China's noteworthy announcement.

36 Corinne Le Quéré, 'Evidence-led climate policy and robust climate governance are key to delivering the Paris Agreement' (2020) $<\mathrm{https} / / / \mathrm{www}$ .theccc.org.uk/2020/10/29/evidence-led-climate-policy-and-robust-climate-governance-are-key-to-delivering-the-paris-agreement/> accessed 8 May 2021. 
goal. ${ }^{37}$ For the land sector, relevant legal areas include that can be cited include:

- Laws regulating the management of agricultural land, forest land, and land-use change;

- Reducing/avoiding emissions through measures such as:

- Deforestation control

- Land-use conversion control

- Fire control

- Spatial planning and land use (including requirements for forest conversion, and how these relate to or include climate goals)

- Enhancing and protecting sinks through measures like:

- Afforestation, reforestation

- Protected areas (Land and Marine)

- Sustainable forest management

- Regulating agriculture (crops/livestock) practices and soil management through measures such as:

- Conservation / regenerative agriculture, organic agriculture, others

- Agroforestry/agroecology

- Regulation of inputs such as fertilizers

- Water management

- Manure management and other types of GHG capture, especially for livestock

- Enabling incentives for sustainable land management through measures such as:

- Inclusion of emissions/removals from land/agriculture in carbon markets and offset mechanisms;

- Payment for Ecosystem Services (PES) in the land/forest sector;

- Tenure security as a precondition for more sustainable natural resources management;

- Other types of fiscal/financial incentives.

- Human rights rules and instruments, including in particular related to the right to a healthy environment, contrasted with property rights / socio-economic rights

- Renewable energy and the use of biomass

This list is just indicative of a variety of approaches and legal areas that can be considered to support climate action in the land sector towards net-zero GHG emissions. There is a need to further understand how legislation in such areas has been used in the past, the lessons learned and insights that they can offer and how they could be further promoted to strengthen climate action towards net-zero GHG emissions.

\section{Content of this Special Issue}

Considering the points above, this Special Issue presents case studies of countries around the world that have enacted legislation enabling relevant climate action in the land sector broadly. The editorial team selected case studies with a view to provide a diverse range of examples, including countries where emissions from the land sector are significant and where relevant initiatives are being undertaken, covering a variety of legal systems, types

37 For a comprehensive overview of the role of legislation in the land and agriculture sectors in promoting climate change mitigation and adaptation actions, see FAO, 'Agriculture and Climate Change: Law and Governance in Support of Climate Smart Agriculture and International Climate Change Goals' (2020) <http://www.fao.org/documents/card/en/c/cb1593en> accessed 8 May 2021. 
of legal instruments and mechanisms. These case studies are presented in order to provide important pathways to support a transition towards net-zero emissions.

- Australia is not only among the world's top GHG emitters, but also a country where the agriculture sector represents an important share of the economy. In addition, Australia is one of the few countries that have legislation setting up mechanisms to generate carbon credits from the agriculture sector and include them in an overall offsetting scheme. The piece on Australia, led by Elena Aydos and Kelsen Gray, present an overview of Australia's main climate policy in the land sector, the Emissions Reduction Fund (ERF), and of the Carbon Farming Initiative, through a critical discussion of the achievements and shortcomings on these initiatives, as well as the difficulties in making such mechanisms work in practice. Australia's experience can provide important insights into other countries willing to include the land sector in carbon pricing mechanisms.

- Brazil is a country of particular relevance with regards to climate change and land use. It is one of the most biodiverse countries in the world, home to the Amazon rainforest and having one of the largest forest coverages in the world, in addition to also having the agriculture sector as a considerable share of its economy. In addition, deforestation and AFOLU account for about $69 \%$ of its GHG emissions, making these sectors as highly relevant for national climate policy (with important international relevance as well). The piece on Brazil, led by Karine Duarte, Marina Demaria Venancio, Paula Silveira Galbiatti, presents an overview of the most relevant Brazilian sectoral policies focused on emissions reductions and land use, including the LULUCF and energy sectors, and explores how Brazilian legislation has comprehensive command and control mechanisms and economic incentives for limiting deforestation and promoting sustainable land management that takes climate change into consideration, while facing important challenges of implementation and enforcement.

- China is the world's leading emitter of GHG and therefore a key player in any discussion regarding the pathway towards net-zero emissions and the achievement of the Paris Agreement, especially in light of China's recent announcement to reach climate neutrality by 2060. The piece on China, written by Yingda Chen, presents a comprehensive overview of Chinese legislation in the climate, forestry and land sectors, and explores how the overall goals of these policy areas in the country have been evolving in relation to the challenges of facing climate change. Importantly, the piece explores how the overall goal of land use management in the country, which historically was linked to protecting agriculture land from conversion to other uses in order to safeguard food security (a key challenge in a country with such a large population) is now evolving to take climate policy goals into account, including the emerging concept of 'ecological land'.

- The European Union's LULUCF Regulation: The European Union's Green Deal launched in December 2019 includes the objective to make the EU 'the first climate neutral continent,' with no net GHGs emissions in 2050 and with economic growth decoupled from resource use. The LULUCF sector is set to play a key role in this connection. In the $\mathrm{EU}$, the LULUCF sector is a net carbon sink of about 284 million tonnes of $\mathrm{CO}_{2}$, and is expected to play an important role for compensating emissions that cannot be reduced, such as those linked with food production and waste. In their article, Annalisa Savaresi and Lucia Perugini analyse the legal dimension of EU action in the LULUCF sector 
and assess the state of play and future measures of the EU to balance emissions and removals in that sector.

- Kenya is a leading African nation where the importance of agriculture to national GDP, and the impacts of climate change on agriculture, adaptation to climate change make it a critical sector to policy and legal priorities. In his piece, Robert Kibugi explores the approach of Kenyan legislation, including the 2016 Climate Change Act, which requires mainstreaming of climate interventions into all government departments and agencies' sectoral strategies, and implementation plans as they implement their respective legislative functions. He discusses how this has been reflected in the agriculture sector, and the role of the Climate Smart Agriculture Strategy for the 2017-2026 period in providing full integration of climate change adaptation and mitigation actions, together with relevant legislation. His analysis point to important conclusions on the need to ensure legal initiatives such as this are given adequate support for implementation, as agriculture laws are lagging behind in integrating express climate change obligations aimed at boosting resilience, or reducing emissions, which could undermine Kenya's low carbon climate resilience pathway to sustainable development.

- New Zealand is one of the few countries to have a zero emissions goal enshrined in law, its Zero Carbon Act. In his article, Trevor Daya-Winterbottom provides a case study of the New Zealand experience in including the land sector in its climate change mitigation strategy. It examines New Zealand's greenhouse gas emissions profile, and explores the Zero Carbon Act's treatment of land sector based emissions, in particular methane, and the policy response of the New Zealand courts, as well as the impact of statutory reforms on public participation, judicial review of emissions targets and local authority action to get to zero emissions.

- In the United States of America (USA), states are leading in a variety of laws that help move land uses toward zero carbon emissions. Warren G. Lavey's piece explores three types of state GHG mechanisms related to land uses that are taking place at state level: to transform land development to meet GHG standards and build resilient communities, to increase carbon storage in forests and agricultural soils, and to assist disadvantaged communities. In addition to discussing how these initiatives contribute towards climate goals such as net-zero, his analysis show how subnational legal and policy action can play an important role in addition or in parallel to efforts undertaken at national levels, showing how multilevel climate policies can be valuable to advance overall net zero ambition.

This Special Issue comes out in good momentum, as the unprecedented scale of COVID-19 economic recovery measures, and the growing number of countries committing to achieving net-zero emissions goals, present an opening for a low-carbon transition that can enable structural changes needed. Seizing this opening will be critical to bridging the emissions gap and moving forward towards the net-zero goal. ${ }^{38}$

We hope that the examples in this Special Issue provide relevant insights and lessons learned for other jurisdictions considering similar action to advance climate goals towards 
net-zero GHG emissions using nature-based solutions and mitigation options in the land sector. This is just the first step towards a broader understanding of the key role of law in supporting this global challenge.

\section{Fabiano de Andrade Correa and Christina Voigt}

Guest Editors 